\title{
Development of gut hormone responses to feeding in neonates
}

\author{
A LUCAS, S R BLOOM, AND A AYNSLEY-GREEN \\ University Department of Paediatrics, John Radcliffe Hospital, Oxford, and Hammersmith Hospital, London
}

SUMMARY The development of the effects of a human milk feed on plasma concentrations of motilin, neurotensin, gastric inhibitory polypeptide, enteroglucagon, gastrin, and secretin were studied in 158 healthy preterm neonates (mean gestation $33 \frac{1}{2}$ weeks) at mean postnatal ages of $2 \frac{1}{2}, 6,13$, or 24 days. Pronounced progressive changes occurred in postprandial hormone responses; these were absent or small in the first days of life and were large by age 24 days. These changes may have important consequences in the adaptation to postnatal life.

After birth there are substantial changes in plasma levels of a wide range of hormones from the gastrointestinal tract. ${ }^{1-4}$ Many of these changes appear to be induced by oral feeding ${ }^{1-2}$ and may play an important role in stimulating some of the adaptations which equip the infant for postnatal nutrition. ${ }^{15-6}$ However, one aspect of neonatal gut hormone physiology which has received little attention is the pattern of gut hormone release induced by feeding. We have shown that several of the gut hormone responses to feeding that have been reported in adults are not seen in 6-day-old term infants. ${ }^{7}$ Little is known about the normal development of these hormone responses after birth, yet such information may be important in the nutritional management of high risk neonates.

We have studied the development of the response of 6 gastrointestinal hormones to a feed in 153 healthy, preterm infants ranging from 2 to 42 days of age.

\section{Patients and methods}

158 healthy preterm infants (birthweights $1968 \pm 32$ $\mathrm{g}$, gestation $33 \cdot 5 \pm 0 \cdot 1$ weeks) were studied, with the approval of the ethics committee. Each infant contributed only one venous blood sample. Postnatal samples were obtained from the back of the hand using an open needle technique, and were taken only at a time when blood was also required for clinical monitoring. The samples were taken at fixed times in relation to feeds (see below), so that analysis of the responses to feeding was based on cross-sectional data.

Each infant was placed in one of four groups according to his postnatal age: $2 \frac{1}{2}$ (range 1-4), 6 (5-7), 13 (9-17), and $24(18-42)$ days. They were fed human milk by nasogastric tube over 5 minutes as described previously. ${ }^{8}$ Infants aged $2 \frac{1}{2}$ days were fed 2-hourly, the other groups 3-hourly. Mean feed volumes were: $8 \mathrm{ml} / \mathrm{kg}, 21.5 \mathrm{ml} / \mathrm{kg}, 22.5 \mathrm{ml} / \mathrm{kg}$, and $22.5 \mathrm{ml} / \mathrm{kg}$ respectively. Blood samples were taken either before or at 30,60 , or 120 minutes after the beginning of a feed: 8-13 samples were taken for each time period. All infants were nursed in incubators at temperatures appropriate for their weights and gestations.

Venous blood samples $(2 \mathrm{ml})$ were collected into cooled heparinised tubes containing aprotonin (Trasylol, Bayer: 2000 KIU units). Plasma motilin, neurotensin, gastric inhibitory polypeptide (GIP), enteroglucagon, gastrin, and secretin were measured using sensitive radioimmunoassays. Motilin, enteroglucagon, and gastrin were assayed as we described previously. 1 Neurotensin was assayed using an antiserum raised to pure synthetic bovine, neurotensin and gel chromatography demonstrated that the antiserum detected two major forms, large and small, the latter coeluting with the synthetic material. ${ }^{9}$ Plasma GIP was assayed using an antiserum raised to pure porcine GIP which showed no cross-reaction with other gut hormones. The assay, which could detect changes of $5 \mathrm{pmol} / 1$ plasma, also detected two forms as analysed by plasma gel chromatography, a small quantity eluting in a large molecular weight position, and a major peak eluting in the position of pure GIP.10 Plasma secretin was measured by an assay technique which used an antibody raised to pure porcine secretin and which detected differences between individual samples of 
$1 \mathrm{pmol} / \mathrm{l}$ with $95 \%$ confidence. ${ }^{11}$ To avoid interassay variation, all samples were analysed in the same assay, which also contained 'control' plasma from 12 healthy adults who had fasted for 4 hours.

Statistical analyses were performed using the Mann-Whitney rank sum test (using a 2-tailed test of significance), unless otherwise stated.

\section{Results}

Motilin. At $2 \cdot 5$ days plasma motilin concentrations of $22 \pm 8 \mathrm{pmol} / \mathrm{l}$ (mean $\pm \mathrm{SEM}$ ) were similar to those found in the fasting adult ( $22 \pm 6)$, with no change after a feed. In association with a postnatal increase in basal levels, which reached a peak at 13 days, there were significant postprandial falls in plasma motilin at 6,13 , or 24 days, the greatest fall being at 13 days from a basal level of $172 \pm 33 \mathrm{pmol} / 1$ to a trough of $68 \pm 12(P<0 \cdot 01)$, Fig. 1 .

Neurotensin. At $2 \frac{1}{2}$ days when basal neurotensin levels $(28 \pm 5 \mathrm{pmol} / \mathrm{l})$ were similar to those found in the adult $(16 \pm 4 \mathrm{pmol} / \mathrm{l})$ there was a rise after a feed to $54 \pm 7 \mathrm{pmol} / 1, \mathrm{P}<0 \cdot 01$. At 6 days basal levels had risen to $66 \pm 13$, and at this age there was no change after a feed. However, as the basal level subsequently declined the postprandial increase became even greater, with a massive and prolonged response on the 24th day from a basal level of $43 \pm 4 \mathrm{pmol} / 1$ to a plateau of $94 \pm 12$ at 30 minutes and $95 \pm 13$ at 60 minutes $(P<0 \cdot 001)$, Fig. 1.
Gastric inhibitory peptide (GIP). Between $2 \frac{1}{2}$ and 13 days there was no increase in GIP after a feed but at 24 days there was a sharp rise from $26 \pm 4 \mathrm{pmol} / 1$ to $43 \pm 3$ at 30 minutes $(P<0 \cdot 01)$. Basal levels were similar at each postnatal age studied (Fig. 2).

Enteroglucagon. Basal plasma concentrations were significantly higher than adult values, with a peak on day 6 of $469 \pm 62 \mathrm{pmol} / \mathrm{l}$ (compared with adults, $37 \pm 5 \mathrm{pmol} / \mathrm{l}, \mathrm{P}<0 \cdot 01)$. The postprandial response became progressively greater throughout the period, reaching a significant increase by 13 days and with the largest response on day 24 from a basal of $238 \pm 53 \mathrm{pmol} / \mathrm{l}$ to a peak of $440 \pm 41$ at 30 minutes $(\mathrm{P}<0 \cdot 01)$, Fig. 2.

Gastrin. At $2 \frac{1}{2}$ and 6 days, basal serum gastrin levels were high $(51 \pm 5$ and $54 \pm 8 \mathrm{pmol} / \mathrm{l})$ compared with the adult value of $7 \pm 2 \mathrm{pmol} / \mathrm{l}, \mathrm{P}<0 \cdot 001$. There was no change after a feed at these ages. By 13 days the basal value had fallen to $24 \pm 1 \mathrm{pmol} / 1$ and there was a rise to $34 \pm 3$ which persisted from 30 to 120 minutes after a feed $(\mathbf{P}<\mathbf{0} \cdot \mathbf{0 1})$. Similar pre- and postprandial values were obtained on day 24 (Fig. 3).

Secretin. There was a small but nonsignificant postprandial increase in plasma secretin at $2 \frac{1}{2}, 6$, and 13 days, but by 24 days, in association with a progressive fall in basal levels, there was a pronounced rise in plasma secretin from a basal level of $2 \cdot 8 \pm 0 \cdot 5$ $\mathrm{pmol} / \mathrm{l}$ to $5 \cdot 1 \pm 0 \cdot 6,60$ minutes after a feed $(\mathrm{P}<0 \cdot 02)$, Fig. 3.
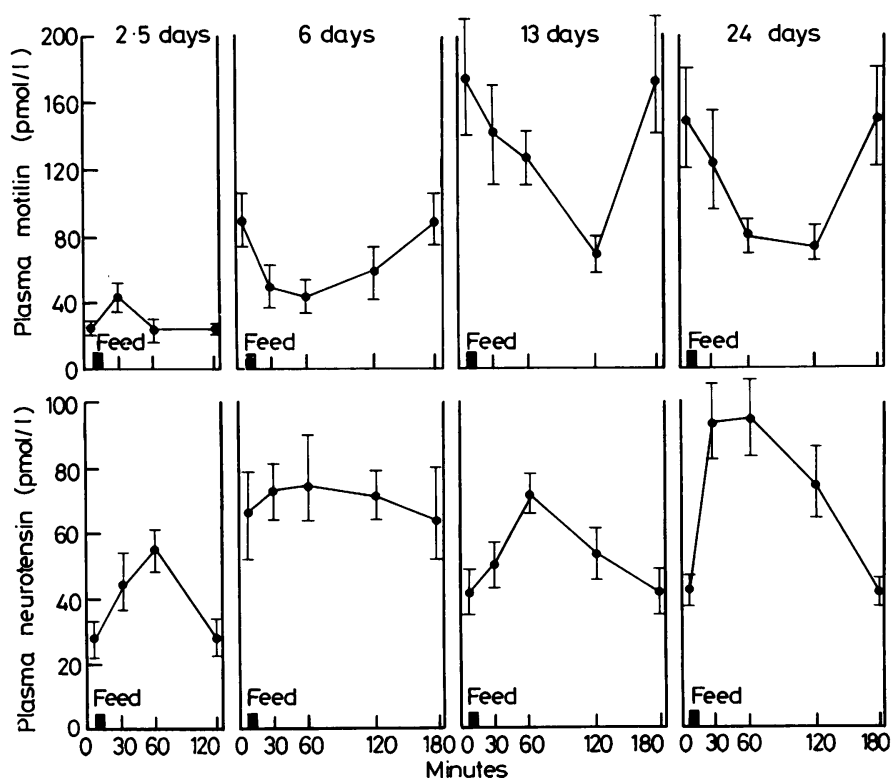

Fig. 1 Development of effect of a milk feed on plasma concentrations of motilin (upper panel) and neurotensin (lower panel). Between 8 and 13 single observations contributed to each mean and standard error bar. 

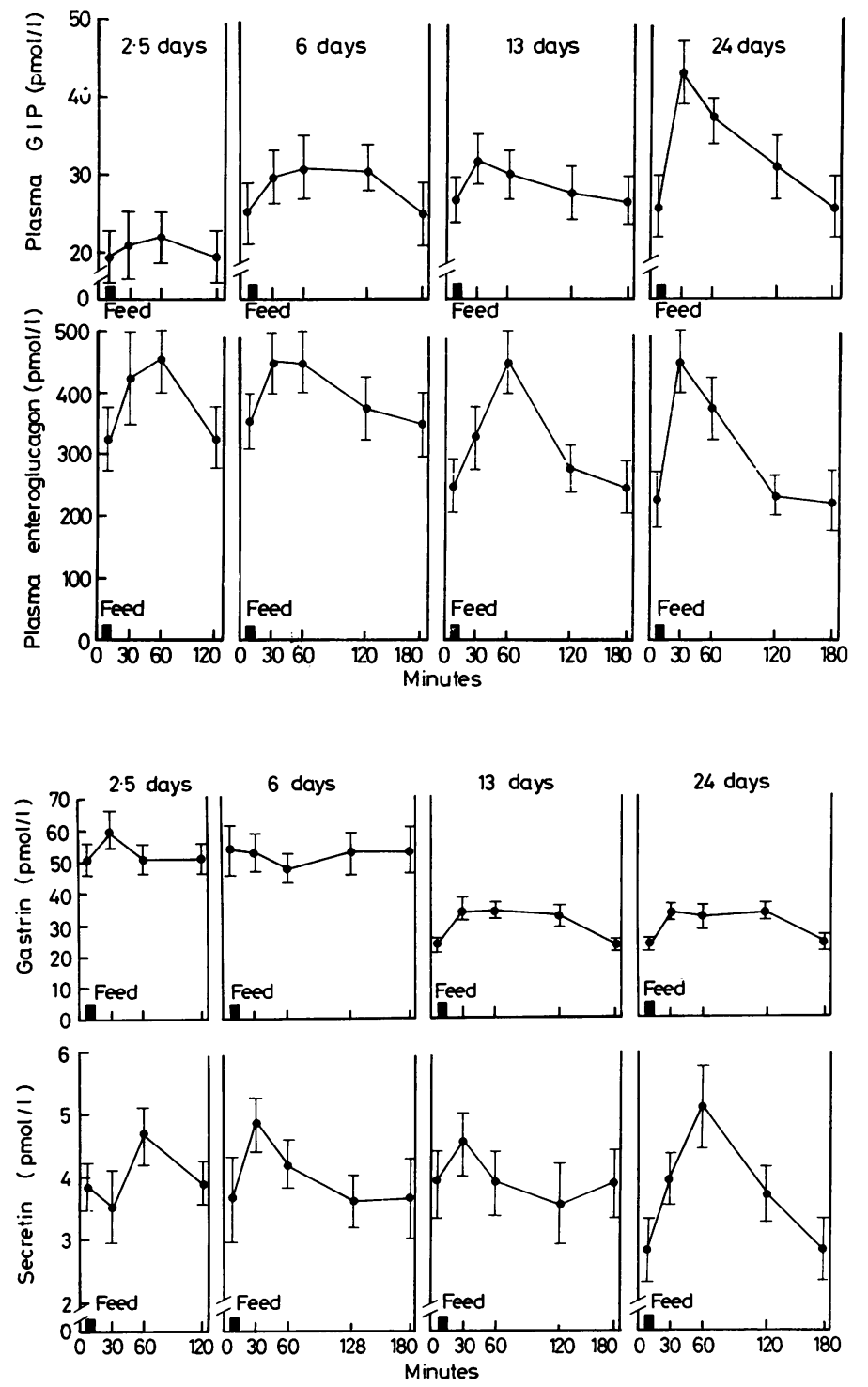

Fig. 2 Development of effect of a milk feed on plasma concentrations of gastric inhibitory polypeptide (GIP) (upper panel), and enteroglucagon (lower panel). Between 8 and 13 single observations contributed to each mean and standard error bar.
Fig. 3 Development of effect of a milk feed on plasma concentrations of gastrin (upper panel) and secretin (lower panel). Between 8 and 13 single observations contributed to each mean and standard error bar.

\section{Discussion}

We have shown that there are pronounced changes in gut hormone response to the physiological stimulus of milk feeding during the neonatal period in preterm infants. One significant finding was that plasma levels of these $\mathbf{6}$ gut hormones tended to be relatively constant during the early neonatal period, with little or no changes after a feed, whereas there were marked phasic responses to feeding by day 24 . These developmental changes occurred despite the fact that at 6,13 , and 24 days the feed volume, feed frequency, and mode of feeding were the same.

The developing rise in GIP after a feed may be a contributory factor in the improvement in glucose tolerance ${ }^{12}$ and increased insulin release ${ }^{13-14}$ described in the neonatal period. GIP is thought to be the principal humoral effector in the enteroinsular axis $^{15-16}$ and its release in adults therefore largely accounts for the increased insulin response to oral compared with intravenous glucose. It has been shown by King et al. ${ }^{17}$ that there is no enhancement 
of insulin release by oral glucose in the first 3 days of life, and this is consistent with our observation of a lack of GIP response at this age, whereas it is possible that the findings of Nakai et al..$^{18}$ of an increased insulin response to oral glucose after age 20 days could be accounted for, in part, by the start of the ability to secrete GIP after a feed.

The physiological role of neurotensin is ill understood in man. There is evidence to suggest that this peptide may be a peptidergic neurotransmitter as well as an ileal hormone. ${ }^{19-20}$ Its pharmacological actions are well known and include inhibition of insulin release, the production of hyperglycaemia, the release of glucagon, increased vascular permeability, and effects on small intestinal motility. ${ }^{19}$ Our studies show that the neurotensin response to a milk feed increases during the neonatal period, and that by day 24 the response is massive, far exceeding that described in the normal adult. ${ }^{21} \mathrm{~A}$ small increase in neurotensin response has been noted in coeliac disease, ${ }^{21}$ presumably due to malabsorption with the passage of food into the terminal ileum where neurotensin-secreting cells are most concentrated. However, if malabsorption accounted for the large neurotensin response in neonates then this response might be expected to decrease rather than increase with age. It is tempting to speculate that the high postprandial plasma neurotensin levels we have described, signify a unique role for this peptide in early life.

Motilin is thought to play a physiological role in stimulating gastric and intestinal motility. ${ }^{22-23}$ High basal levels in neonates have been reported previously by us ${ }^{8}$ and others. ${ }^{3}$ We have now shown that during the neonatal period, as basal levels rise, there is an increasingly large decline in plasma motilin after a feed. In adults, oral glucose produces a fall in plasma motilin, but a mixed meal, oral fat, and gastric distension all stimulate a rise. ${ }^{24}$ On this basis, a postprandial fall in motilin was an unexpected finding after a milk feed in neonates. It is possible, however, that our results should be interpreted as a preprandial increase in motilin rather than a postprandial decline. Motilin is thought to have an interdigestive role ${ }^{23}$ and perhaps this role is exaggerated in the neonatal period, possibly because of the relatively large feed volume consumed at this age. ${ }^{25}$ In view of the effects of motilin on gastric contractility, we have also considered the possibility that a preprandial rise in plasma motilin could account for the so-called hunger contractions of the stomach described in term and preterm neonates. ${ }^{26}$

We have shown that basal circulating plasma concentrations of the other 3 hormones-enteroglucagon, gastrin, and secretin-reach high levels in the early neonatal period and subsequently decline. The occurrence of phasic changes in the plasma levels of these hormones after a feed towards the end of the neonatal period could perhaps, be considered as due to a fall in the basal plasma concentration, rather than to a rise in the postprandial level. Thus the total area under the response curve between successive feeds actually decreased with postnatal age, and consequently the development of a postprandial increase may be more apparent than real. However, it is not known if gut hormone receptors adapt to constant stimuli. If they do, then constant gut hormone levels may tend to have less effect and the start of phasic hormone changes could result in enhanced target cell stimulation.

This report has been confined to preterm infants. Because we obtained blood samples only at times when blood was required for clinical monitoring we were unable to extend studies to the term infant after day 6 . Nevertheless, the results of studies on term infants reported elsewhere, ${ }^{7}$ are not comparable with those on preterm infants because of the different methods of feeding and the smaller quantity of milk consumed by term neonates in the first 6 days of life. However, on day 6 gut hormone responses in term and preterm infants are qualitatively similar, with the same tendency to small postprandial hormone changes.

In conclusion, we have shown that there are substantial developmental changes in gut hormone responses to milk feeding during the neonatal period in preterm infants and, in particular, there is a progressive development of hormone responses to feeding. In adults a mixed meal is followed by plasma increases in all the hormones reported in this study, ${ }^{21}{ }^{24}$ but it is difficult to compare adults with preterm neonates as they differ with respect to mode of food intake (nasogastric feeding in preterm infants), feed-to-feed interval, and volume of food consumed in relation to body weight. Clearly the development of phasic hormonal feed responses in neonates represents progression towards the adult pattern. However, we have shown that even towards the end of the first month of life, there are qualitative and quantitative differences between the gut hormone response patterns in neonates and those reported by others in adults, which may not relate entirely to differences in the mode of nutrition. The studies reported refer to healthy preterm neonates, and our observations should form the basis for further studies on sick preterm infants. Since the gut hormones may have important effects on postnatal adaptation, it is arguable that feeding regimens for sick newborn infants should be designed, as far as possible, to preserve the normal pattern of hormone responses seen at this age. 


\section{References}

1 Lucas A, Adrian T E, Christofides N, Bloom S R, Aynsley-Green A. Plasma motilin, gastrin, and enteroglucagon and feeding in the human newborn. Arch Dis Child 1980; 55: 673-7.

2 Lucas A, Adrian T E, Bloom S R, Aynsley-Green A. Plasma secretin in neonates. Acta Paediatr Scand 1980; 69: 205-10.

3 Mitznegg P, Domschke W, Bloom S R, et al. Physiology of motilin I. In: Bloom S R, ed. Gut hormones. Edinburgh: Churchill Livingstone, 1978: 339-42.

4 Rogers I M, Davidson D C, Lawrence J, Ardill J, Buchanan K D. Neonatal secretion of gastrin and glucagon. Arch Dis Child 1974; 49: 796-801.

5 Johnson L R. New aspects of the trophic action of gastrointestinal hormones. Gastroenterology 1977; 72: 788-92.

6 Aynsley-Green A, Lucas A, Bloom S R. The effect of feeds of differing composition on entero-insular hormone secretion in the first hours of life in human neonates. Acta Paediatr Scand 1979; 68: 265-70.

7 Lucas A, Adrian T E, Aynsley-Green A, Bloom S R. Differences in alimentary hormone response between breast and bottle fed infants. Lancet $1980 ;$ i: 1267-9.

8 Lucas A, Bloom S R, Aynsley-Green A. Metabolic and endocrine events at the time of the first feed of human milk in preterm and term infants. Arch Dis Child 1978; 53: 731-6.

9 Blackburn A M, Bloom S R. Radioimmunoassay for neurotensin in human plasma. $J$ Endocrinol 1979; 83: 175-81.

10 Sarson D L, Bryant M G, Bloom S R. Radioimmunoassay for gastric inhibitory polypeptide (GIP) in human plasma. $J$ Endocrinol 1980 ; in press.

11 Häcki W H, Bloom S R, Mitznegg P, et al. Plasma secretin and pancreatic bicarbonate response to exogenous secretin. Gut 1977; 18: 191-5.

12 Von Euler U, Larsson Y, Persson B. Glucose tolerance in the neonatal period and during the first six months of life. Arch Dis Child 1964; 39: 393-6.

13 Isles T E, Dickson M, Farquhar J W. Glucose tolerance and plasma insulin in newborn infants of normal and diabetic mothers. Pediatr Res 1968; 2: 198-208.

14 Lowy C, Schiff D. Urinary excretion of insulin in the healthy newborn. Lancet 1968; i: 225-7.
15 Dupre J, Ross S A, Watson D, Brown J C. Stimulation of insulin secretion by gastric inhibitory polypeptide in man. J Clin Endocrinol Metab 1973; 37: 826-8.

16 Creutzfeldt W. The incretin concept today. Diabetologia $1979 ; 16: 75-85$.

17 King K C, Schwartz R, Yamaguchi K, Adam P J. Lack of gastrointestinal enhancement of the insulin response to glucose in newborn infants. $J$ Pediatr 1977 ; 91 : 783-6.

18 Nakai T, Hayashi M, Kandzawa Y, Kosaka K, Kigawa $\mathrm{T}$, Sakamoto $\mathrm{S}$. Alterations of insulin-secreting response to glucose in human infants during the early postnatal period. Endocrinol Jpn 1976; 23: 61-4.

19 Brown M, Rivier J, Kobayashi R, Vale W. Neurotensinlike and bombesin-like peptides: CNS distribution and actions. In: Bloom S R, ed. Gut hormones. Edinburgh: Churchill Livingstone, 1978: 550-8.

20 Buchan A M J, Polak J M, Sullivan S, Bloom S R, Brown M, Pearse A G E. Neurotensin in the gut. In: Bloom S R, ed. Gut hormones. Edinburgh: Churchill Livingstone, 1978: 544-9.

21 Besterman H S, Bloom S R, Sarson D L, et al. Guthormone profile in coeliac disease. Lancet 1978; i: 785-8.

${ }^{22}$ Ruppin H, Sturm G, Westhoff D, et al. Effect of 13-Nlemotilin on small intestinal transit time in healthy subjects. Scand J Gastroenterol (Suppl) 1976; 11 : No 39, 85-8.

23 Vantrappen G, Janssens J, Peeters J, Bloom S R, Christofides N D, Hellemans J. Intraduodenal $\mathrm{pH}$, motilin, and interdigestive motor complex in man (abstract). Scand J Gastroenterol (Suppl) 1978; 13: 49 No, 190.

24 Christofides N D, Bloom S R, Besterman H S. Physiology of motilin II. In: Bloom S R, ed. Gut hormones. Edinburgh: Churchill Livingstone, 1978; 343-50.

25 Faber H K. Food requirements in newborn infants; a study of the spontaneous intake. Am J Dis Child 1922; 24: 56-72.

26 Taylor R. Hunger in the infant. Am J Dis Child 1917; 14: 233-57.

Correspondence to Dr A Lucas, University Department of Paediatrics, Addenbrooke's Hospital, Hills Road, Cambridge CB2 2QQ.

Received 4 September 1979 